\title{
Ovarian development in intrauterine growth-retarded and normally developed piglets originating from the same litter
}

\author{
P. Da Silva-Buttkus ${ }^{1}$, R. van den Hurk ${ }^{1}$, E. R. te Velde ${ }^{2}$ and M. A. M. Taverne ${ }^{1}$ \\ ${ }^{1}$ Department of Farm Animal Health, Faculty of Veterinary Medicine, Utrecht University, Yalelaan 7, \\ 3584CL Utrecht, The Netherlands; and ${ }^{2}$ Division of Obstetrics, Neonatology and Gynecology, \\ University Hospital Utrecht, Heidelberglaan 100, 3584 CX Utrecht, The Netherlands
}

Epidemiological studies in humans linking adult disease to growth in utero indicate that prenatal life is a critical period for the appropriate development of the reproductive axis. The aim of this study was to compare ovarian development in intrauterine growth-retarded and normally grown piglets originating from the same litter. Intrauterine growthretarded piglets (runts) were identified on the basis of statistical analysis of the birth weight distribution within each litter. At birth, ovaries were collected from runt piglets $(n=14)$ and their respective mean weight (normal, $n=14)$ littermates. Ovaries were weighed and fixed, and development of ovarian germ cells was quantified in haematoxylin-eosin-stained paraffin wax sections using an image analysis system. Germ cell loss, using an in situ TdTmediated dUTP nick-end labelling (TUNEL) assay for DNA fragmentation, and follicle cell activity, using immunohistochemistry to demonstrate vimentin, were studied in ovarian sections. At birth, body weight and absolute ovarian mass were significantly lower in runt piglets compared with their respective normally grown littermates (body weight: $733 \pm 38.5$ versus $1530 \pm 39.7 \mathrm{~g}$; ovarian mass: $51 \pm 3.0$ versus $108 \pm 9.6 \mathrm{mg} ; P<0.001$ for both). In the ovary, the proportion of nests of oogonia, the number of oocytes and TUNEL-positive cells, and the localization and intensity of vimentin immunoreactivity were not different between runt and normal littermates. However, runt piglets had more primordial follicles $(268 \pm 18.6$ versus $235 \pm 20.1$ per $\mathrm{mm}^{2}$ of cortex; $\left.P<0.05\right)$, fewer primary follicles $\left(11 \pm 2.0\right.$ versus $20 \pm 3.0$ per $\mathrm{mm}^{2}$ of cortex; $P<$ 0.001 ) and no secondary follicles compared with normal piglets. These findings indicate that intrauterine growth retardation delayed follicular development in pig ovaries at birth.

\section{Introduction}

Perturbed prenatal growth has a major impact on neonatal survival and it has been suggested that growth restriction during fetal life is also associated with a range of adult pathologies in humans (Barker et al., 1993), such as increased risk of developing type 2 diabetes, hypertension and cardiovascular disease (Barker, 1995). Other reports indicate that altered growth in utero may be associated with the development of reproductive disorders in later life, including altered timing of onset of puberty (Ibãnez et al., 2000a), reduced size of the uterus and the ovaries (Ibãnez et al., 2000b), and earlier menopause (Cresswell et al., 1997). In these reports it is postulated that these postnatal disorders may derive from altered fetal reproductive organogenesis. Indeed, the development of the hypothalamic-pituitary-gonadal axis occurs largely during prenatal life and, within the ovary, processes such as migration, proliferation, degeneration and meiosis of germ cells, and folliculogenesis determine

Email: p.pereira-dasilva@vet.uu.nl the follicle population at birth and potentially the number of follicles that can be recruited during postnatal life.

Studies on animals and humans have begun to address more specifically the effect of altered prenatal growth on fetal ovarian development and to date have reported contradictory findings. De Bruin et al. (2001) failed to demonstrate an effect of severe growth restriction on ovarian development in mid-gestation human fetuses that died prenatally. In contrast, a significantly lower number of follicles was found in growth-restricted late gestation sheep fetuses (Da Silva et al., 2002a). Therefore, there is a need to clarify the relationship between prenatal growth retardation and ovarian development using other animal models, keeping in mind that the possible exhaustion of follicle reserves has stronger implications for humans, as, compared with domestic species, their period of reproductive activity is much longer (Faddy et al., 1992).

In pigs, fetal growth retardation is an important determinant of perinatal mortality (van der Lende et al., 2001), contributing to a considerable economic loss in the pig industry worldwide (Varley, 1995). During the early neonatal period, growth-retarded piglets have a lower capacity to compete with heavier littermates for 


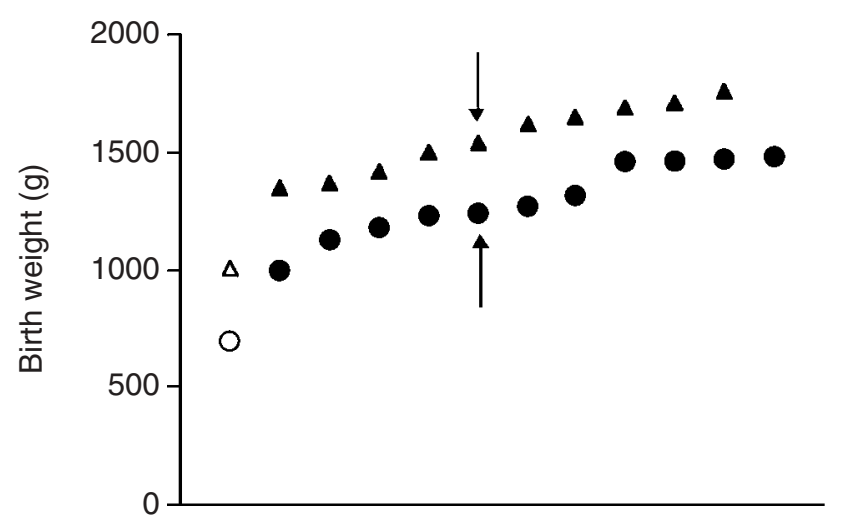

Fig. 1. Illustration of representative litters that contained intrauterine growth-retarded piglets analysed on the basis of the intrinsic variation in birth weight. For the present study, an identified runt female piglet in each litter $(\bigcirc: 690 \mathrm{~g}$ birth weight; $\triangle: 1010 \mathrm{~g}$ birth weight) was pair-matched with a normally sized female littermate (arrows), which was selected as the female piglet with the birth weight closest to the mean weight of the litter which consisted of both female and male piglets. $\boldsymbol{\Delta}$ and $\boldsymbol{\bullet}$ : each symbol represents a littermate of the runt female piglet.

colostrum, have less energy reserves to adapt to extrauterine life (Hayashi et al., 1987; Fraser et al., 1995) and show proportionally smaller liver and kidneys but not brain (Ritacco et al., 1997; Bauer et al., 2000). Furthermore, these piglets, compared with normal littermates, grow at a slower rate and have compromised renal excretory function (Bauer et al., 2000), glucose tolerance (Poore and Fowden, 2002) and muscle fibre development (Handel and Stickland, 1987) during postnatal life. Therefore, the naturally occurring form of growth retardation in pigs, and the possibility of comparison with a normally grown littermate, makes growth-retarded piglets a useful model in which to investigate the repercussions of suboptimal growth in reproductive organ development, without the confounding effects of different maternal genotype, nutrition and husbandry conditions. Several methods have been developed to recognize intrauterine growth-retarded piglets within a litter and have been reviewed by Ashworth et al. (2001). It is generally accepted that they should not be identified just as the lightest individuals in a litter but rather that they are in fact 'outliers' in an otherwise normal within-litter distribution (Wootton et al., 1983; van der Lende et al., 1990; Finch et al., 1999).

The aim of the present study was to compare (i) germ cell development, (ii) germ cell loss and (iii) the structural integrity of all types of ovarian cell and viability of the granulosa cell layer between ovaries collected from naturally occurring intrauterine growth-retarded newborn piglets and their respective normally developed littermates. Germ cell development was determined by classical histological procedures, whereas germ cell loss was examined by detection of DNA fragmentation (using TdT-mediated dUTP nick-end labelling (TUNEL) assay).
Appropriate development of all types of ovarian cell was examined by immunohistochemical demonstration of the intermediate filament protein vimentin. Reorganization of vimentin-containing filaments is associated with changes in cellular shape and with various cellular functions such as intracellular transport, nucleus-cell surface interactions and nuclear functions (Goldman et al., 1986; Aumüller et al., 1992), and is recognized as a marker of granulosa cell viability (van den Hurk et al., 1995). It is proposed that study of the pig ovary could complement the recent efforts to understand the relationship between impairment of prenatal growth and ovarian development.

\section{Materials and Methods}

\section{Animals and experimental design}

The experiment was approved by the Animal Ethics Committee of the Veterinary Faculty of Utrecht University. The weight and sex of live-born piglets from litters produced by cross-bred sows (Dutch Landrace/ Yorkshire) in the same experimental farm (Sterksel, The Netherlands) were examined within 12-24 h after birth. Litters were statistically analysed at the farm on the basis of number of live piglets born during one farrowing by the biological mother, duration of gestation and variation in birth weight within each litter. The statistical computerized method used to determine the within-litter birth weight distribution was based on procedures for the identification of multiple 'outliers' in small samples and has been described in detail by van der Lende et al. (1990). The use of this method allows identification of low birth weight piglets that are 'outliers' in an otherwise normally distributed population and are referred to as intrauterine growth-retarded piglets (colloquially denominated as 'runts'). In the present study, 14 of 73 litters contained intrauterine growth-retarded female piglets; seven litters had one runt piglet and seven litters had two runt piglets, but only one runt piglet was studied per litter. The mean \pm SEM duration of gestation and litter size for these litters were $115 \pm 0.3$ days and $12 \pm 0.6$ piglets $(n=14)$, respectively.

At the farm, each identified intrauterine growthretarded female piglet was pair-matched with a normally developed littermate, which was selected as the female piglet with the birth weight closest to the mean birth weight of the litter which consisted of both female and male piglets (Fig. 1). These pairs of piglets were removed from the mother and killed (T61: $250 \mathrm{mg}$ embutramide $\mathrm{ml}^{-1}, 50 \mathrm{mg}$ mebezoniumjodide $\mathrm{ml}^{-1}$ and $5 \mathrm{mg}$ tetracainehydrochloride $\mathrm{ml}^{-1} ; 1.5 \mathrm{ml}$ intracardiac administration; Hoechst Roussel Vet., Amsterdam). The crown-rump length, girth at the umbilicus and biparietal head diameter were measured. The abdominal cavity was opened and the ovaries were dissected, weighed and fixed. The values for the ovarian mass refer to the total combined mass of the left and right ovaries. 


\section{Tissue fixation and preparation}

The right ovary was immersion-fixed in Bouin's solution at room temperature $\left(20-22^{\circ} \mathrm{C}\right)$ for $20 \mathrm{~h}$ and was then rinsed and stored in $70 \%(\mathrm{v} / \mathrm{v})$ ethanol. The ovary was dehydrated in a series of ethanol, cleared in xylene and impregnated in paraffin wax. The ovary was subsequently bisected transversely and both parts were embedded in the same paraffin wax block. The ovaries were cut into serial sections (thickness $5 \mu \mathrm{m}$ ) and each twentieth section was stained routinely with haematoxylineosin for estimation of germ cell development. A few sections were also mounted on polylysine (Menzel-Gläser, Braunschweig)-coated slides for immunohistochemical study of vimentin. The left ovary was immersion-fixed in $4 \%(\mathrm{w} / \mathrm{v})$ phosphate-buffered formaldehyde at $4{ }^{\circ} \mathrm{C}$ for $20 \mathrm{~h}$, rinsed in $70 \%(\mathrm{v} / \mathrm{v})$ ethanol and embedded in paraffin wax as described above. The ovaries were cut into serial sections ( $5 \mu \mathrm{m}$ thickness) and each twentieth section was mounted on polylysine-coated slides for examination of DNA fragmentation, which is characteristic of apoptosis.

\section{Morphometric analysis}

Germ cells were classified histologically as oogonia (germ cells devoid of follicle cells with an intact nuclear membrane), oocytes (germ cells undergoing meiosis and devoid of follicle cells), primordial follicles (oocyte surrounded by a layer of flattened follicle cells), primary follicles (enlarged oocyte completely surrounded by one layer of cuboidal follicle cells) or secondary follicles (enlarged oocyte surrounded by two or more concentric layers of cuboidal cells) as described by Oxender et al. (1979). Oocytes surrounded by a single granulosa layer that consisted of both flattened and cuboidal cells were classified as primordial follicles. Stained ovarian sections were examined under a microscope using a semi-automatic image analysis system. The equipment used consisted of a light microscope (Zeiss Photomicroskop II) with a $\times 1$ or $\times 16$ objective coupled to a camera (Sony b/w CCD camera type XC-77CE, frame size $752 \times 574$ pixels; 256 grey levels) and a specific computer program which was designed using the image analysis KS400 version 3.0 software package (Carl Zeiss Vision, Munchen). Ovary area was measured in each twentieth stained section, using a $\times 1$ objective, to select the sections around the largest diameter. Each section was produced on to the computer monitor and ovary and cortical areas were measured using the image analysis software. Thereafter, microscopic fields ( $\times 16$ objective) of the ovarian cortex (approximately $0.20 \mathrm{~mm}^{2}$ each, with one side of the field placed on the surface epithelium) were projected on to the computer screen and using the computer program, all nests of oogonia, oocytes and primordial, primary and secondary follicles were outlined by the operator using the computer mouse. These microscopic images were measured automatically and converted into $\mathrm{mm}^{2}$.
Counts were exported to a Microsoft Excel program and the number of germ cells per $\mathrm{mm}^{2}$ of cortex was calculated. This procedure was repeated for the two sections around the largest diameter (100 $\mu \mathrm{m}$ apart) and an index of the number of oocytes and follicles was calculated by averaging the results. Only follicles in which the nucleus of the oocyte was visible were counted. The same quantitative method was used uniformly for all ovaries. In this way, at least $35-40 \%$ of the ovarian cortex of a section was quantified. The applicability of this procedure was verified in another study (Da Silva et al., 2002b) in which the results obtained using two sections at the largest diameter of a fetal pig ovary (day 100 after mating) were found to represent the mean number of germ cells per $\mathrm{mm}^{2}$ counted in approximately every twentieth section of an entire ovary (the correlation was $0.79)$.

\section{TUNEL assay}

TUNEL assay for DNA fragmentation was performed using an in situ cell death detection kit (Roche, Mannheim) according to the manufacturer's protocol. In brief, sections approximately around the largest diameter were deparaffinized and rehydrated. Endogenous cellular peroxidase was blocked with $3 \%(\mathrm{v} / \mathrm{v}) \mathrm{H}_{2} \mathrm{O}_{2}$ in methanol for $10 \mathrm{~min}$. After a phosphate-buffered saline (PBS) wash, terminal deoxynucleotidyl transferase (TdT) enzyme solution was added to each section to label single and double DNA strand breaks with fluorescein, and the reaction was incubated for $1 \mathrm{~h}$ in a humidified chamber at $37^{\circ} \mathrm{C}$. A negative control section without the addition of the TdT enzyme was also included. After the sections were washed in PBS, anti-fluorescein antibody Fab fragments conjugated with horseradish peroxidase were added to each section and incubated for $30 \mathrm{~min}$ in a humidified chamber at $37^{\circ} \mathrm{C}$. The sections were washed in PBS and bound antibodies were covered with $0.3 \mu \mathrm{g} 3,3^{\prime}$-diaminobenzidine tetrachloride $\mu \mathrm{I}^{-1}$ (DAB; Sigma, Poole) in PBS, to which $0.03 \%(\mathrm{v} / \mathrm{v}) \mathrm{H}_{2} \mathrm{O}_{2}$ was added. The slides were washed in water, counterstained with Mayer's haematoxylin and dehydrated in increasing concentrations of ethanol and mounted. TUNEL-positive cells (brown staining) were counted in the two sections (100 $\mu \mathrm{m}$ apart) using a light microscope at a magnification of $\times 400$. As the presence of TUNEL-positive cells was observed in the ovarian cortex only, the positive cell counts were then averaged and expressed per $\mathrm{mm}^{2}$ of ovarian cortex.

\section{Immunohistochemical staining}

The intermediate filament vimentin was used as a marker for structural integrity of all types of ovarian cell, with special emphasis on the viability of the granulosa cell layer. The immunohistochemical staining technique was similar to that reported by van den Hurk et al. 
Table 1. Body weight, body measurements, ovary mass and number of germ cells in normal and intrauterine growthretarded (runt) piglets at birth

\begin{tabular}{|c|c|c|c|}
\hline \multirow[b]{2}{*}{ Characteristic } & \multicolumn{2}{|c|}{ Growth status } & \multirow[b]{2}{*}{ Significance } \\
\hline & Normal & Runt & \\
\hline Number of piglets & 14 & 14 & na \\
\hline $\begin{array}{l}\text { Body weight (g) } \\
\text { (range) }\end{array}$ & $\begin{array}{c}1530 \pm 39.7 \\
(1290-1770)\end{array}$ & $\begin{array}{l}733 \pm 38.5 \\
(520-1010)\end{array}$ & $P<0.001$ \\
\hline Crown-rump length $(\mathrm{cm})$ & $31 \pm 0.4$ & $25 \pm 0.5$ & $P<0.001$ \\
\hline Umbilical girth $(\mathrm{cm})$ & $25 \pm 0.5$ & $19 \pm 0.7$ & $P<0.001$ \\
\hline Biparietal head diameter $(\mathrm{cm})$ & $6.0 \pm 0.1$ & $5 \pm 0.1$ & $P<0.001$ \\
\hline Ovarian mass (mg) & $108 \pm 9.6$ & $51 \pm 3.0$ & $P<0.001$ \\
\hline Relative ovary mass (g ovary kg body weight ${ }^{-1}$ ) & $0.07 \pm 0.006$ & $0.07 \pm 0.005$ & ns \\
\hline Nests of oogonia $(\%)^{*}$ & $0.8 \pm 0.22$ & $1.2 \pm 0.22$ & ns \\
\hline Number of oocytes ${ }^{\dagger}$ & $171 \pm 17.8$ & $188 \pm 19.2$ & ns \\
\hline Number of primordial follicles ${ }^{\dagger}$ & $235 \pm 20.1$ & $268 \pm 18.6$ & $P<0.05$ \\
\hline Number of primary follicles ${ }^{\dagger}$ & $20 \pm 3.0$ & $11 \pm 2.0$ & $P<0.001$ \\
\hline Number of secondary follicles ${ }^{\dagger}$ & $1.0 \pm 0.5$ & $0.0 \pm 0.0$ & $P<0.05$ \\
\hline Number of apoptotic cells ${ }^{\dagger}$ & $10 \pm 2.7$ & $10 \pm 1.6$ & $\mathrm{~ns}$ \\
\hline
\end{tabular}

Values are mean \pm SEM.

*(Area of nests of oogonia/area of cortex examined) $\times 100$.

$\dagger$ Values are expressed per $\mathrm{mm}^{2}$ of ovarian cortex.

na: not applicable; ns: not significant.

(1995) with some modifications. In brief, ovarian sections that had been fixed with Bouin's solution and paraffin wax were deparaffinized and rehydrated. Endogenous peroxidase activity was blocked with $1 \%(\mathrm{v} / \mathrm{v}) \mathrm{H}_{2} \mathrm{O}_{2}$ in methanol for $30 \mathrm{~min}$. The intermediate filament protein vimentin was detected with monoclonal mouse antibody (clone V9) purchased from Biogenex (distributed by Klinipath, Duiven) at a dilution of 1:150. Biotinylated horse anti-mouse immunoglobulin (DAKO, Hamburg), diluted 1:125, was used as the second antibody. The detection of the bound antibody was accomplished by the avidin-biotin immunoperoxidase system (Vectastain Elite ABC kit; Vector Laboratories, Burligame). Negative control slides were prepared by substitution of mouse IgG for the primary antibody. Ovarian sections of 42-day-old pigs, which contain more mature follicles, were used as a positive control. All sections were incorporated in the same immunohistochemical procedure. Staining was evaluated semiquantitatively by light microscopy and estimated on a scale from - to +++ in all types of ovarian cell. A score of,,-+++ or +++ indicated absent, weak, moderate or strong staining intensity, respectively. The estimated intensity of staining was compared between ovarian sections derived from runt and normally grown piglets.

\section{Statistical analysis}

All values are presented as mean \pm SEM. Body weight and conformation and ovarian data were compared between runt piglets and their respective normally grown littermates using paired Student's $t$ test. A Wilcoxon signed rank test was used for the comparison of the number of secondary follicles because number of secondary follicles was the only variable to fail the normality test. Data for numbers of oocytes, follicles and TUNELpositive cells were transformed (natural logarithm) to normalize variation before statistical analysis (except for secondary follicles) and are presented as mean number per $\mathrm{mm}^{2}$ of ovarian cortex. Correlation analysis was performed using Pearson's product moment test. Values were considered significant at $P<0.05$.

\section{Results}

Body size, absolute and relative ovarian masses for normal piglets and their intrauterine growth-retarded littermates at birth are shown (Table 1). Body weight, crown-rump length, umbilical girth and biparietal head diameter were all significantly lower $(P<0.001)$ in runt piglets than in their normally sized littermates. Although absolute ovarian mass was lower $(P<0.001)$ in runt piglets compared with their normally grown littermates, relative ovary mass (that is, expressed in terms of body weight) was not different between the two groups of piglets (Table 1). Ovarian area and area of the cortical region (around the largest diameter) were significantly lower in runt piglets compared with normal littermates (ovarian area: $5.96 \pm 0.49$ versus $7.71 \pm 0.60 \mathrm{~mm}^{2}$; area of cortical region: $4.13 \pm 0.39$ versus $5.04 \pm$ $0.45 \mathrm{~mm}^{2}$; both $\left.P<0.05\right)$ and were positively correlated with ovarian mass $(r=0.537$ and 0.648 , respectively; $n=28 ; P<0.01$ ).

Neither the proportion of nests of oogonia nor the number of oocytes per unit of ovarian cortex was significantly influenced by naturally occurring growth 

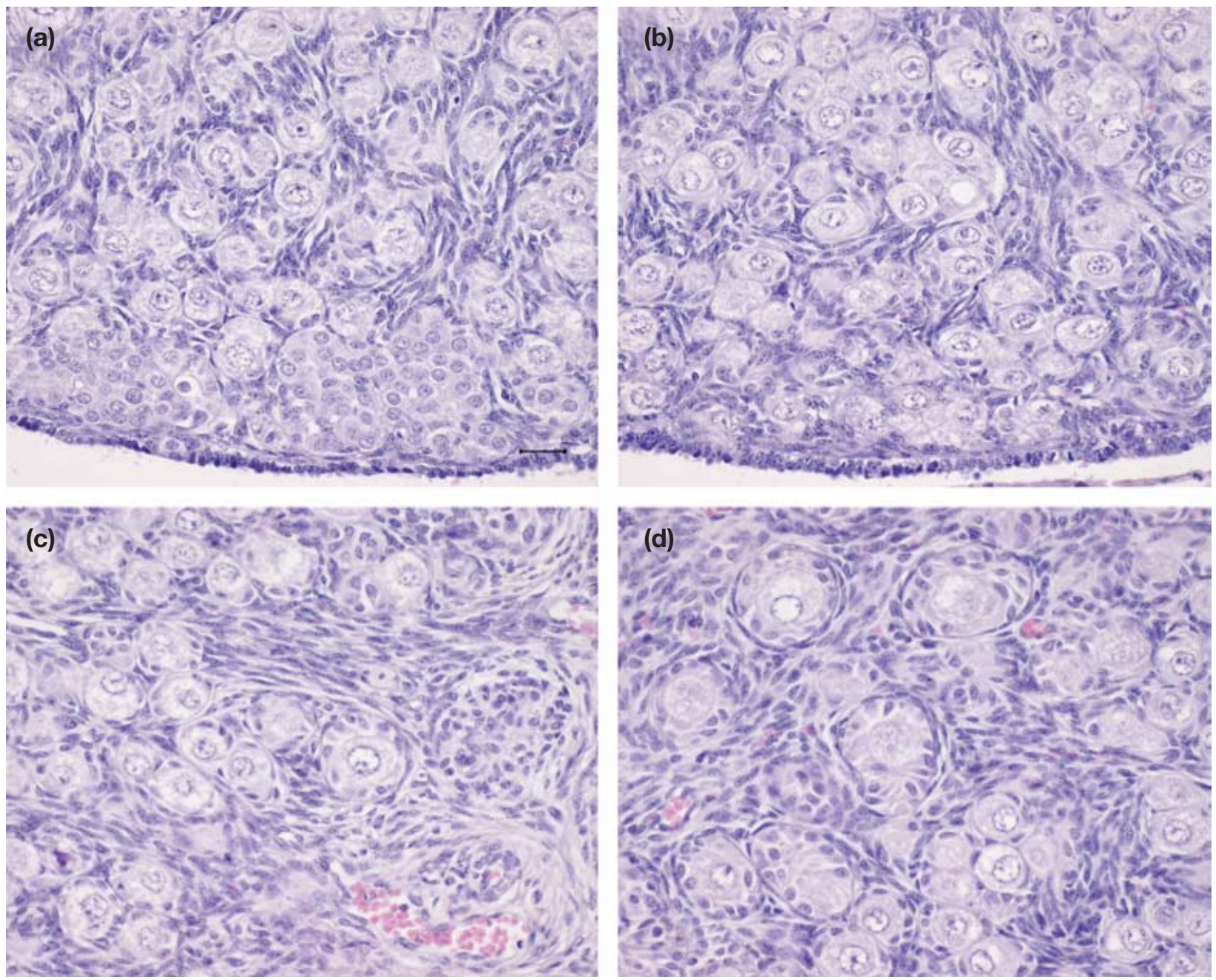

Fig. 2. Haematoxylin-eosin-stained sections of pig ovaries at birth. $(a, c)$ Runt piglets showed an abundant incidence of oogonial nests and fewer primary follicles per $\mathrm{mm}^{2}$ of cortex compared with $(\mathrm{b}, \mathrm{d})$ normally grown piglets. Scale bar represents $25 \mu \mathrm{m}$.

retardation (Table 1), despite the tendency for a higher abundance of oogonia in the cortex of runt piglets (Fig. 2a,b). Runt piglets had higher $(P<0.05)$ numbers of primordial follicles compared with their normally sized littermates (Table 2); however, there were significantly fewer $(P<0.001)$ primary follicles in runt piglets than in their normal littermates (Table 1 and Fig. 2c,d). Furthermore, ovaries from runt piglets were devoid of secondary follicles, whereas some secondary follicles could be observed in ovarian sections from their normally sized littermates (Table 1). Overall, the number of primary follicles was positively correlated with birth weight $(r=0.399 ; n=28 ; P<0.05)$ and ovary mass $(r=0.424$; $n=28 ; P<0.05)$.

The number of TUNEL-positive cells present per unit of ovarian cortex did not differ between runt piglets and their normally sized littermates (Table 1). DNA fragmentation of germ cells predominantly represented isolated oocytes (Fig. 3) and no sign of degeneration was detected in follicular structures in either the oocyte or follicular cells.

Moderate vimentin immunoreactivity was observed in the cell cords surrounding the nests of oogonia and oocytes, but was absent in oogonia, oocytes and in the surface epithelium (Fig. 4). Immunoreactivity was generally weak in pre-granulosa cells of primordial follicles and granulosa cells of primary and secondary follicles, whereas it was strong in follicles of the postnatal ovarian tissue that was used as positive control. However, no differences in either intensity or localization of vimentin staining were observed between runt piglets and normally sized piglets, although no secondary follicles were present in the ovaries of runt piglets.

\section{Discussion}

In the present study, the naturally occurring model of growth retardation provided by piglets was used and 
Table 2. Estimated proportion of nests of oogonia, number of oocytes and of primordial, primary and secondary follicles per mm ${ }^{2}$ of ovarian cortex in normal and intrauterine growth-retarded runt littermate piglets at birth

\begin{tabular}{|c|c|c|c|c|c|c|c|c|c|c|}
\hline \multirow[b]{3}{*}{ Litter } & & & \multicolumn{8}{|c|}{ Number per $\mathrm{mm}^{2}$ of ovarian cortex } \\
\hline & \multicolumn{2}{|c|}{ Nests of oogonia (\%)* } & \multicolumn{2}{|c|}{ Oocytes } & \multicolumn{2}{|c|}{ Primordial follicles } & \multicolumn{2}{|c|}{ Primary follicles } & \multicolumn{2}{|c|}{ Secondary follicles } \\
\hline & Normal & Runt & Normal & Runt & Normal & Runt & Normal & Runt & Normal & Runt \\
\hline 1 & 0.58 & 1.73 & 95 & 114 & 233 & 256 & 27 & 8 & 0 & 0 \\
\hline 2 & 0.62 & 0.87 & 142 & 268 & 340 & 307 & 6 & 3 & 0 & 0 \\
\hline 3 & 1.65 & 2.73 & 207 & 202 & 226 & 276 & 6 & 3 & 0 & 0 \\
\hline 4 & 0.09 & 2.66 & 151 & 141 & 310 & 247 & 16 & 6 & 0 & 0 \\
\hline 5 & 0.01 & 0.20 & 128 & 300 & 386 & 476 & 12 & 5 & 0 & 0 \\
\hline 6 & 1.43 & 1.95 & 184 & 203 & 201 & 274 & 13 & 7 & 1.0 & 0 \\
\hline 7 & 0.32 & 0.29 & 154 & 78 & 187 & 218 & 32 & 7 & 1.2 & 0 \\
\hline 8 & 0.01 & 0.26 & 166 & 129 & 178 & 174 & 24 & 15 & 1.4 & 0.6 \\
\hline 9 & 0.05 & 0.90 & 264 & 269 & 147 & 259 & 39 & 14 & 1.4 & 0 \\
\hline 10 & 1.85 & 0.97 & 102 & 177 & 144 & 199 & 14 & 17 & 7.1 & 0 \\
\hline 11 & 1.12 & 0.60 & 214 & 92 & 154 & 252 & 13 & 11 & 1.0 & 0 \\
\hline 12 & 0.16 & 0.98 & 125 & 275 & 239 & 243 & 42 & 27 & 0 & 0 \\
\hline 13 & 2.65 & 1.43 & 338 & 208 & 241 & 290 & 18 & 22 & 0 & 0 \\
\hline 14 & 0.61 & 1.56 & 131 & 176 & 303 & 287 & 24 & 14 & 0 & 0 \\
\hline
\end{tabular}

$*$ (Area of nests of oogonia/area of cortex examined $) \times 100$.
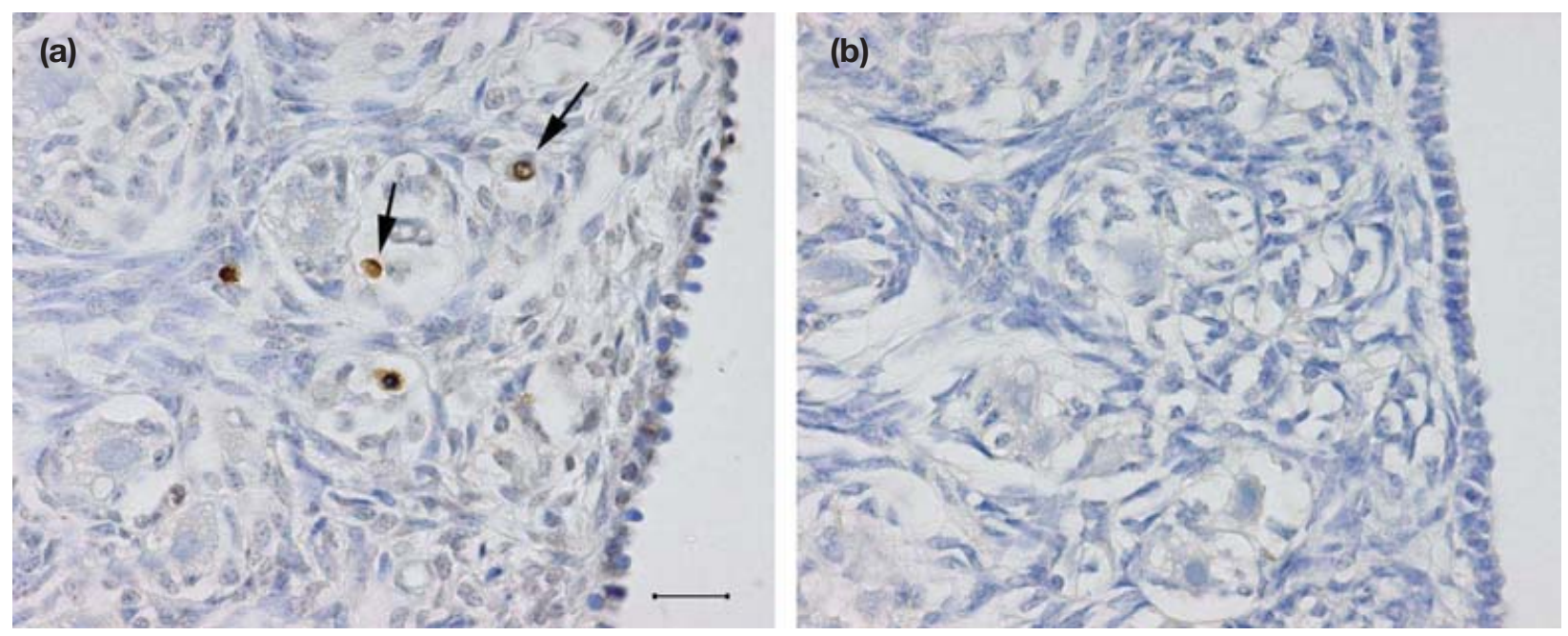

Fig. 3. (a) In situ 3' end-labelling of germ cells in the ovarian cortex of a pig ovary at birth; TdT-mediated dUTP nick end-labelled cells were brown (arrows). (b) Negative control. Scale bar represents $20 \mu \mathrm{m}$.

intrauterine growth-retarded piglets were identified using a well defined statistical method (van der Lende et al., 1990). This statistical approach allowed comparison of ovarian germ cell development in intrauterine growthretarded (runt) piglets with their respective normally grown (control) littermates, born at normal term, thereby avoiding possible confounding influences of genetic background and housing conditions. The results of the present study indicate that compromised prenatal growth may have delayed the normal pattern of follicular development in pig ovaries as demonstrated, at birth, by the higher number of primordial follicles, the lower number of primary follicles and absence of secondary follicles in the ovaries of runt piglets compared with normally developed littermates.

In the present study, runt piglets showed a reduction in body weight which was associated with a significant reduction in absolute ovarian mass compared with their normally sized littermates at birth. In contrast, relative ovarian mass was not influenced by growth retardation and the values for the normally developed piglets are in agreement with data reported by Colenbrander et al. (1983). These findings indicate that the decrease in ovary mass was proportional to that in body weight in the present study. The reports regarding the effects of intrauterine growth retardation on organ masses 

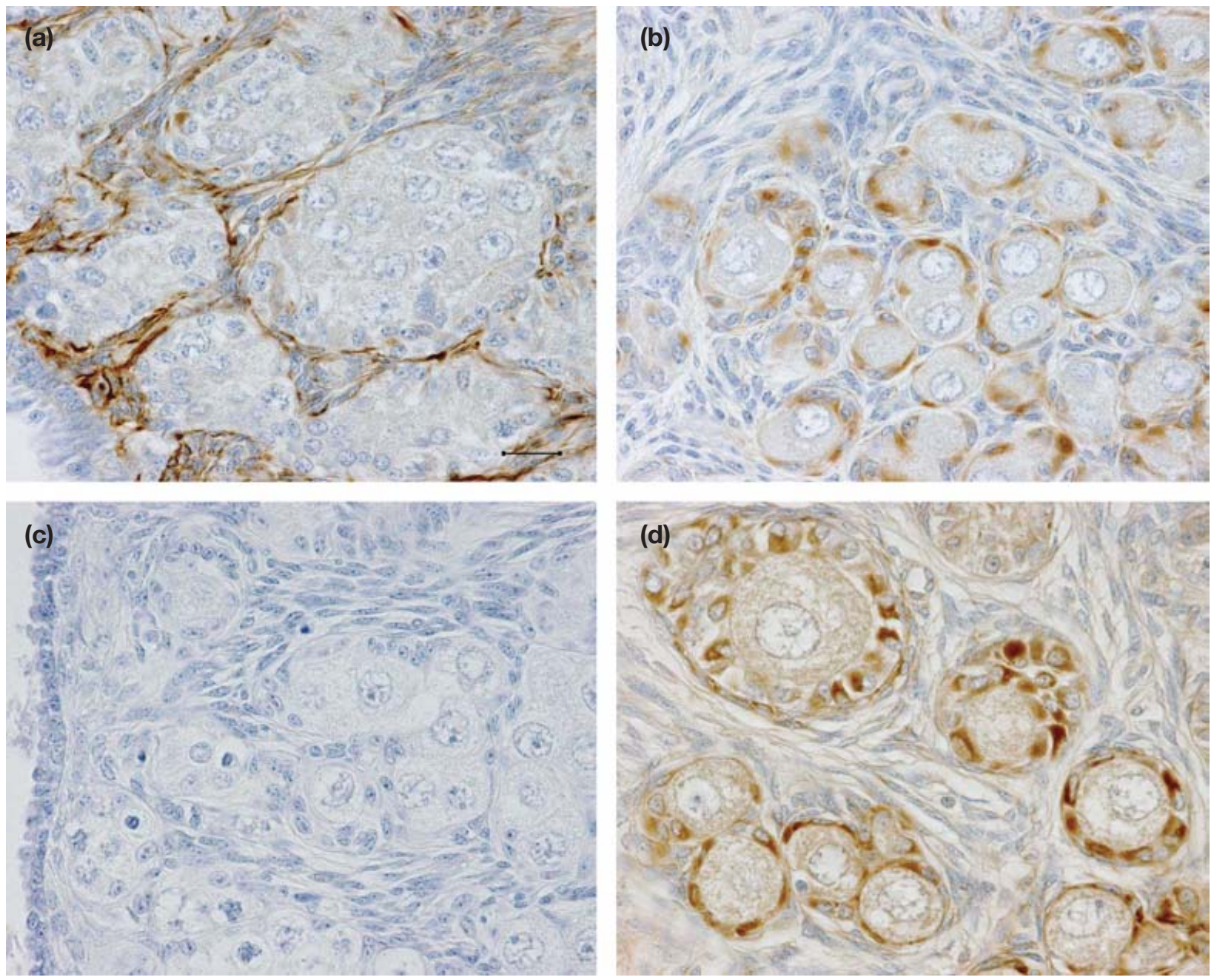

Fig. 4. Vimentin immunoreactivity in pig ovaries. (a) Vimentin staining present in cords surrounding the nests of oogonia at birth. (b) Vimentin staining in pre-granulosa cells of primordial follicles at birth. (c) Negative control at birth. (d) Vimentin reaction intensified in the granulosa layer of primordial and primary follicles at day 42 of age (positive control). Scale bar represents $20 \mu \mathrm{m}$.

generally only include vital organs and rarely include the masses of reproductive organs (Widdowson, 1971; Flecknell et al., 1981; Bauer et al., 1998). Such reports indicate that in growth-retarded piglets, the masses of the liver, heart, kidneys and lungs decrease considerably with decreased body weight, being adequate for their smaller size; whereas the masses of the brain, pituitary and adrenal glands do not change significantly with body weight. Despite this, the effect of growth retardation on ovarian mass reported in the present study does not appear to have been mediated by inadequate development of the pituitary gland, because deprivation of pituitary hormones as a result of decapitation of pig fetuses at day 42 of gestation did not alter ovarian mass at day 112 of gestation (Colenbrander et al., 1983).

Within the ovary, the proportion of nests of oogonia in the ovarian cortex was not significantly different between runt and normal littermate piglets born at normal term.
This observation appears to indicate that proliferation and degeneration of ovarian germ cells were not compromised by prenatal growth retardation. However, it does not exclude a possible adverse effect on these two aspects of germ cell development (and subsequent recovery) at an earlier stage. Reduced growth of pig fetuses can already be evident by day 35 (van der Lende et al., 1990) and day 44 (Cooper et al., 1978) of gestation. Finch et al. (1999) reported that poor fetal growth was detected as early as day 30 of gestation, probably related to inadequate placental ability to deliver nutrients into the fetal compartment. By this stage, germ cells are proliferating in the pig ovary, reaching a peak number by about day 50 of gestation at the time when germ cell degeneration becomes markedly accentuated (Black and Erickson, 1968). The slight tendency for more oogonial nests in ovaries from runt piglets at birth may be indicative of the importance of examining germ cell proliferation and 
degeneration at mid-gestation to provide better insight into whether compromised fetal growth exerts differential mitotic or degenerative effects or both on development of ovarian germ cells.

Naturally occurring growth retardation in piglets in the present study was associated with a higher number of ovarian primordial follicles per $\mathrm{mm}^{2}$ of ovarian cortex at birth. This finding was intriguing in view of the fact that the number of oocytes was identical between runt and normally sized littermates. In contrast, there was a significant reduction in the number of primary and secondary follicles in runt piglets and, collectively, these findings point to the occurrence of a delay in follicular development in these piglets, probably in the activation of primordial follicles. Indeed, the gross morphological structure of an ovary from a runt piglet at term resembled that of an ovary collected from a normally developed piglet several weeks before birth (Da Silva et al., 2002b). Fetal growth restriction did not influence the number of follicles in the ovaries of human fetuses at weeks 26-31 of gestation (de Bruin et al., 2001). In contrast, placentally induced fetal growth restriction in sheep reduces the number of follicles in the ovaries of late gestation fetuses (Da Silva et al., 2002a). Nevertheless, comparisons among species need to be addressed with care because the ovary of the pig (polytocous animal), in contrast to sheep and humans, contains proliferating oogonia and numerous oocytes until approximately day 20 of postnatal life (pig: Garrett and Guthrie, 1999; sheep: Sawyer et al., 2002; human: Kurilo, 1981), which could potentially be recruited to form follicles or to simply degenerate. Study of runt and normally sized piglets during early postnatal life is required to address whether a 'catch up' process will contribute to the primary follicle pool in the ovaries of runt piglets. Primordial follicles express various factors such as growth differentiation factor 9 (GDF-9) and c-kit-kit ligand complex that help to initiate follicle growth (Picton, 2001; Richards, 2001), and it is possible that their different timing of expression may have been involved in the formation of fewer primary follicles in runt piglets. The significant ovarian differences in the number of primary and secondary follicles, coupled with the major reduction in ovarian mass, between runts and normally grown littermate piglets, offer a unique opportunity to study the factors associated with primordial follicle activation and growth that have the ultimate potential to influence age at puberty, ovulation rate and subsequent litter size in sows. Hence, altered growth in utero, associated with poor early postnatal growth, when ovarian development is still proceeding, may impair fertility in sows and should be the subject of further research. Indeed, it has been reported that slow-growing gilts are older at first mating than are fast-growing gilts (Tummaruk et al., 2000). However, owing to the present interest in relating low birth weight with premature menopause and prospects of fertility in humans, one hypothesis was that perturbed fetal growth could compromise the primordial follicle pool contained in the ovaries at birth. The number of primordial follicles per unit area of pig ovary found in the present study did not confirm this contention. Further methods (for example, collagenase digestion of an entire ovary to assess total number of germ cells) are needed to confirm this observation, as ovarian mass in naturally growth-retarded piglets was significantly lower than that of normal sized littermates.

In the present study, the number of degenerative TUNEL-positive cells was not different between runts and normal piglets. On the basis of their location, size and shape, these cells were predominantly isolated oocytes and occurred in very small numbers $( \pm 5 \%)$. This finding is supported by the study of Vaskivuo et al. (2001), in which a few apoptotic oocytes were also determined in human fetuses close to term. One possible explanation for the findings of the present study could be that at birth there is little germ cell loss. It has been reported that high cell death occurs just after the number of germ cells reaches a peak (at approximately day 50 of gestation) in pig ovaries (Black and Erickson, 1968; Garrett and Guthrie, 1999). This is also true for other species such as cows and humans (Reynaud and Driancourt, 2000). In women, it has been reported that $9 \%$ of the germ cell nuclei are apoptotic in mid-gestation ovaries (De Pol et al., 1997). Thus, as previously suggested, germ cell death should be examined at an earlier stage of gestation. Furthermore, necrosis is another mode of cell death that, although not examined in the present study, could potentially occur in follicles of the pig ovary (van den Hurk et al., 1999).

The findings of the present study regarding the localization of vimentin immunoreactivity are in agreement with previous studies in human (Santini et al., 1993) and cow (van den Hurk et al., 1995) ovaries. Reorganization of vimentin-containing filaments occurs in mitotic cells (Lamb et al., 1989), whereas their increased number is correlated with an alteration of cellular structure (Aumüller et al., 1992). Vimentin-containing filaments are absent in germ cells but they appear to be an important feature of the differentiation events leading to the final phenotype of granulosa cells and, therefore, vimentin is considered as a marker of granulosa cell viability (van den Hurk et al., 1995). The absence of differences in either localization or intensity of vimentin staining between runt and normally grown piglets indicates that the follicles contained healthy active granulosa cells in both groups of piglets.

In conclusion, the results of the present study indicate that, in the pig model, naturally compromised prenatal growth in utero had an effect on ovarian organogenesis. The reduced number of primary follicles and absence of secondary follicles in the ovaries of runts compared with normally grown littermate piglets may be attributable to a delay in activation of primordial follicles. No differences were observed with respect to either normal 
development of follicular cells or their degeneration. It would be interesting to determine whether these ovarian changes that were initiated during fetal life are maintained during postnatal life and to assess their impact on adult reproductive performance.

The authors cordially thank $\mathrm{H}$. van de Kant and $\mathrm{R}$. Molenbeek for technical assistance, and H. van Dijk and the staff of the experiment farm of pig husbandry 'Zuid- en West-Nederland' for helping with the animal work. The provision of the statistical model by $\mathrm{T}$. van der Lende, the statistical advice of $\mathrm{C}$. Looman and financial support by B. Kemp are gratefully acknowledged. P. Da Silva-Buttkus was funded by the Portuguese Ministry of Science and Technology.

\section{References}

Ashworth CJ, Finch AM, Page KR, Nwagwu MO and McArdle HJ (2001) Causes and consequences of fetal growth retardation in pigs Reproduction Supplement $\mathbf{5 8} 233-246$

Aumüller G, Schulze C and Viebahn C (1992) Intermediate filaments in Sertoli cells Microscopic Research and Technique 20 50-72

Barker DJP (1995) Fetal origins of coronary heart disease British Medical Journal 311 171-174

Barker DJP, Gluckman PD, Godfrey KM, Harding JE, Owens JA and Robinson JS (1993) Fetal nutrition and cardiovascular disease in adult life Lancet 341 938-941

Bauer R, Walter B, Hoppe A, Gaser A, Lampe V, Kauf E and Zwiener U (1998) Body weight distribution and organ size in newborn swine (Sus scrofa domestica) - a study describing an animal model for asymmetrical intrauterine growth retardation Experimental Toxicology and Pathology 50 59-65

Bauer R, Walter B, Inring W, Kluge H, Lampe V and Zwiener U (2000) Altered renal function in growth-restricted newborn piglets Pediatric Nephrology 14 735-739

Black JL and Erickson BH (1968) Oogenesis and ovarian development in the prenatal pig The Anatomical Record 161 45-56

Colenbrander B, van Rossum-Kok CMJE, Oxender WD and Wensing CJG (1983) Ovarian development in control and decapitated pig fetuses Biology of Reproduction 29 217-223

Cooper JE, John M, McFadyen IR and Wootton R (1978) Early appearance of 'runting' in piglets Veterinary Record 102 529-530

Cresswell JL, Egger P, Fall CHD, Osmond C, Fraser RB and Barker DJP (1997) Is the age of menopause determined in utero? Early Human Development 49 143-148

Da Silva P, Aitken RP, Rhind SM, Racey PA and Wallace JM (2002a) Impact of maternal nutrition during pregnancy on pituitary gonadotrophin gene expression and ovarian development in growth-restricted and normally grown late gestation sheep fetuses Reproduction $\mathbf{1 2 3}$ 769-777

Da Silva P, van den Hurk R, Ashworth CJ, Lea RG, te Velde ER and Taverne MAM (2002b) Fetal ovarian development in inadequately grown porcine fetuses Reproduction Abstract Series $\mathbf{2 8}$ Abstract 69

De Bruin JP, Nikkels PGJ, Bruinse HW, van Haaften M, Looman CWN and te Velde ER (2001) Morphometry of human ovaries in normal and growth-restricted fetuses Early Human Development 60 179-192

De Pol A, Vaccina F, Forabosco A, Cavazzuti E and Marzona L (1997) Apoptosis of germ cells during human prenatal oogenesis Human Reproduction 12 2235-2241

Faddy MJ, Gosden RG, Gougeon A, Richardson SJ and Nelson JF (1992) Accelerated disappearance of ovarian follicles in mid-life: implications for forecasting menopause Human Reproduction 7 1342-1346

Finch AM, Zuur G and Ashworth CJ (1999) Differential growth of porcine fetuses: timing of IUGR Early Human Development 55 185-186

Flecknell PA, Wootton R, John M and Royston JP (1981) Pathological features of intra-uterine growth retardation in the piglet: differential effects on organ weights Diagnostic Histopathology 4 295-298
Fraser D, Phillips PA, Thompson BK, Pajor EA, Weary DM and Braithwaite LA (1995) Behavioural aspects of piglet survival and growth. In The Neonatal Pig: Development and Survival pp 287-312 Ed. MA Varley. CAB International, Wallingford

Garrett WM and Guthrie HD (1999) Expression of Bcl-2 and $3^{\prime}-\beta$ hydroxysteroid dehydrogenase protein during oocyte and follicle development in fetal and post-natal pig ovaries Reproduction, Fertility and Development 11 463-470

Goldman RD, Goldman AE, Green KJ, Jones JCR, Jones SM and Yang H-Y (1986) Intermediate filament networks: organization and possible functions of a diverse group of cytoskeletal elements Journal of Cell Science Supplement 5 69-97

Handel SE and Stickland NC (1987) The growth and differentiation of porcine skeletal muscle fibre types and the influence of birth weight Journal of Anatomy 152 107-119

Hayashi M, Ingram DL and Dauncey MJ (1987) Heat production and respiratory enzymes in normal and runt newborn piglets Biology of the Neonate 51 324-331

Ibãnez L, Ferrer A, Marcos MV, Hierro FR and de Zegher F (2000a) Early puberty: rapid progression and reduced final height in girls with low birth weight Pediatrics 106 E72

Ibãnez L, Potau N, Enriquez G and de Zegher F (2000b) Reduced uterine and ovarian size in adolescent girls born small for gestational age Pediatric Research 47 575-577

Kurilo LF (1981) Oogenesis in antenatal development in man Human Genetics 57 86-92

Lamb NJC, Fernandez A, Feramisco JR and Welch WJ (1989) Modulation of vimentin containing intermediate filament and phosphorylation in living fibroblasts by the cAMP-dependent protein kinase Journal of Cell Biology 108 2409-2422

Oxender WD, Colenbrander B, van de Wiel DFM and Wensing CJ (1979) Ovarian development in fetal and prepubertal pigs Biology of Reproduction 21 715-721

Picton HM (2001) Activation of follicle development: the primordial follicle Theriogenology 55 1193-1210

Poore KR and Fowden AL (2002) The effect of birth weight on glucose tolerance in pigs at 3 and 12 months of age Diabetologia 45 1247-1254

Reynaud K and Driancourt MA (2000) Oocyte attrition Molecular and Cellular Endocrinology 163 101-108

Richards JS (2001) Perspective: the ovarian follicle - a perspective in 2001 Endocrinology 142 2184-2193

Ritacco G, Radecki SV and Schoknecht PA (1997) Compensatory growth in runt pigs is not mediated by insulin-like growth factor I Journal of Animal Science 75 1237-1243

Santini D, Ceccarelli C, Mazzoleni G, Pasquinelli G, Jasonni VM and Martinelli GN (1993) Demonstration of cytokeratin intermediate filaments in oocytes of the developing and adult human ovary Histochemistry 99 311-319

Sawyer HR, Smith P, Heath DA, Juengel JL, Wakefield J and McNatty KP (2002) Formation of ovarian follicles during fetal development in sheep Biology of Reproduction 66 1134-1150

Tummaruk P, Lundeheim N, Einarsson S and Dalin AM (2000) Factors influencing age at first mating in purebred Swedish Landrace and Swedish Yorkshire gilts Animal Reproduction Science 63 241-253

Van den Hurk R, Dijkstra G, van Mil FN, Hulshof SCJ and van den Ingh SGAM (1995) Distribution of the intermediate filament proteins vimentin, keratin, and desmin in the bovine ovary Molecular Reproduction and Development 41 459-467

Van den Hurk R, Bevers MM and Dieleman SJ (1999) Folliculogenesis and oocyte development in mammals (livestock animals). In Comparative Endocrinology and Reproduction pp 296-312 Eds KP Joy, A Krishna and C Haldar. Narosa Publishing House, New Delhi

Van der Lende T, Hazeleger W and de Jager D (1990) Weight distribution within litters at the early foetal stage and at birth in relation to embryonic mortality in the pig Livestock Production Science 26 53-65

Van der Lende T, Knol EF and Leenhouwers JI (2001) Prenatal development as a predisposing factor for perinatal losses in pigs Reproduction Supplement 58 247-261 
Varley MA (1995) Introduction. In The Neonatal Pig: Development and Survival pp 1-13 Ed. MA Varley. CAB International, Wallingford

Vaskivuo TE, Anttonen M, Herva R, Billig $H$, Dorland M, te Velde ER, Stenbäck F, Heikinheimo $\mathbf{M}$ and Tapanainen JS (2001) Survival of human ovarian follicles from fetal to adult life: apoptosis, apoptosisrelated proteins, and transcription factor GATA-4 Journal of Clinical Endocrinology and Metabolism 86 3421-3429

Widdowson EM (1971) Intra-uterine growth retardation in the pig. I. Organ size and cellular development at birth and after growth to maturity Biology of the Neonate 19 329-340
Wootton R, Flecknell PA, Royston JP and John M (1983) Intrauterine growth retardation detected in several species by non-normal birth weight distributions Journal of Reproduction and Fertility 69 659-663

Received 20 February 2003.

First decision 10 April 2003.

Revised manuscript received 30 April 2003.

Accepted 19 May 2003. 